\title{
Метафорическая экспликация концепта «Америка» в когнитивном контексте Г. Д. Гребенщикова
}

\author{
ZHANNA SELIVERSTOVA, ZHANYL ZHUNUSSOVA \\ L. N. Gumilyov Eurasian National University, 2 Satpayev str., KZ-010008 Astana \\ E-mail: seliverst.zh@gmail.com, zhanyl08@mail.ru
}

(Received: 15 August 2018; accepted: 27 October 2018)

\begin{abstract}
In the present paper, the peculiarities of G. Grebenshchikov's American text are analyzed from a theoretical point of view and metaphor is considered as a cognitive mechanism. The authors' metaphoric models serve as a key for understanding the writer's intention and help to overcome the difficulties of perception of the writer's text. The metaphors "America Mechanism" and "America - Organism" are revealed and compared. Grebenshchikov's conceptual blend "American Babylon" is reconstructed. The research was carried out on the basis of archive documents from the writer's personal materials.
\end{abstract}

Keywords: America, G. Grebenshchikov, metaphor, conceptual blend, cognitive context

\section{Введение}

Традиции изучения интеллектуального наследия русско-американского литератора Г. Д. Гребенщикова (1883-1964) до сих пор ограничивались, как правило, историко-культурными и литературоведческими методами исследования (см. Росов 2004, Сирота 2007, ЧеРняева 2015). Однако необходимо более углубленное проникновение в когнитивный контекст писателя для дешифровки кода его творческой мысли, индивидуально-авторских особенностей в конструировании концептов. С этой целью для анализа текста мы привлекаем инструменты когнитивной лингвистики, опираясь на разработки теории концептуальной метафоры (LAKOFF-JOHNSON 2003) и теории концептуальной интеграции (FAUCONNIER-TURNER 2002). Данные теории базируются на метафоричности процессов концептуализации человеческого мышления. Поэтому, рассматривая процесс возникновения концептуальной метафоры в авторском тексте на примере индивидуально-авторского концепта «Америка», мы попытаемся раскрыть когнитивные механизмы лингвокреативной деятельности Г. Д. Гребенщикова.

В основе исследования находится понимание концепта не как монолитной, фиксированной и статичной структуры, а как динамичного, контекстнозависимого и мультипликативного представления (см. GIBBS 1996 и др.). Язык в этом отношении, как отмечают лингвокогнитологи, выступает как «одно из средств доступа к сознанию человека», которое позволяет «познать и эксплицировать значительную часть концептуального содержания сознания» (ПоПОВА-СТЕРнИН 2007: 14). 


\section{Когнитивный контекст Г. Д. Гребенщикова в американский период}

Когнитивный контекст Г. Д. Гребенщикова, отражающий его опыт познания мира, был значительно расширен после эмиграции в Америку. Длительное пребывание (1924-1964) в новой языковой и культурной среде, ее постижение и осмысление привело к концептуализации представлений писателя о новой реальности.

Литературный текст Г. Д. Гребенщикова американского периода представляет собой доказательный лингвистический материал для выявления и подтверждения индивидуально-авторских особенностей концепта «Америка». «Страна действительно неограниченных возможностей» (ГРеБенщиков 1: 298), «страна сурового труда и славных достижений» (ГреБЕнщиков 4: 385), «страна чудес и страшного грехопадения» (ГреБЕнщиков 6: 426) - вот ряд номинаций, репрезентирующих несколько противоречивый, на первый взгляд, характер авторской концептуализации. Для разрешения подобных противоречий мы и привлекаем к анализу текста механизмы концептуальной метафоризации.

Доказательной базой исследования послужили архивные материалы из личного фонда Г. Д. Гребенщикова, которые хранятся в Государственном музее истории литературы, искусства и культуры Алтая (ГМИЛИКА, Барнаул, Россия), а также материалы собрания сочинений писателя в 6 томах (см. ГРЕБЕНщИКОВ).

\section{Метафорические модели концепта «Америка»: теория и экспликация}

Одним из уровней познания концепта «Америка» в тексте Г. Д. Гребенщикова является выявление концептуальных метафор. Являясь важнейшим когнитивным механизмом осмысления действительности, концептуальные метафоры позволяют глубже изучить исследуемый концепт, содержание которого раскрывается через сопоставление с уже известным концептом (см. LAKOFF-JOHNSON 2003).

Кроме того, при изучении метафорической репрезентации концепта следует учитывать и социокультурный фактор. И хотя Дж. Лакофф и М. Джонсон упоминают социокультурный контекст как одну из составляющих процесса порождения концептуальных метафор, социокультурный анализ в целом находится «на глубокой периферии их теории» (ГлеБкин 2012: 54). На наш взгляд, учет социокультурного фактора, наряду с соматическим, абсолютно необходим. И в этом плане, мы ориентируемся на позицию венгерского лингвиста Золтана Кёвечеша, который предложил обновленные контуры теории концептуальной метафоры с учетом социокультурного пласта (см. KöVECSES 2005). 


\section{Метафорическая модель «Америка - Механизм»}

С названных выше теоретических позиций мы рассматриваем концептуальную метафорическую модель «Америка - Механизм». Следует отметить, что метафора «Механизм» в принципе является «системообразующей для западной культуры Нового времени» (ГлЕькин 2012: 51). Поэтому не случайно, что Г. Д. Гребенщиков, осмысливая механистичную и благоустроенную действительность современной ему Америки, довольно часто использует в своих текстах метафору «Механизма». Например: «Настоящая деловая, созидающая Америка работает ритмично, точно, но спокойно» (ГРЕБЕНщИКов 6: 387).

Концепт «Америка» Г. Д. Гребенщикова - примечательный механизм. С одной стороны, он хрупок и зависим от кризисных явлений: «вся финансовая мощь Америки, вся торговая, промышленная и деловая жизнь могли быть расстроены в один день» (ГРЕБенщиков-Ч: 4), - подобно тому, как расстраивается тонкий музыкальный инструмент, который под влиянием внешнего воздействия теряет правильную высоту звуков, свой строй. С другой стороны, «Америка» - это мощный агрегат, способный не только увлечь своей энергией, но и сломать, растоптать, уничтожить индивидуальность отдельной личности.

В первые годы пребывания в Америке Г. Гребенщикова увлекают «американские масштабы деловитости», он позитивно отмечает энергичность, находчивость, подвижность, свойственные американскому народу (ГРЕБЕнщиков 4: 474). Американская энергия в когнитивном контексте писателя сопоставима с беспредельной механической энергией, на которую способен только искусственно созданный и слаженный механизм при идеальных условиях работы. Но в механическом водовороте американской жизни человек становится лишь маленькой деталью, которая может быть переработана без ущерба для самого механизма. Г. Д. Гребенщиков чувствует это на себе: «Могла бы в пыль нас растоптать механическая, сумасшедшая в спешке Америка, но не растоптала, не дались» (ГРеБенщиков 5: 375). «Одно могу сказать, сломать меня Америке не удалось и, думаю, не удастся» (ГреБенщиков 2002: 249).

В рассмотренном значении метафоры «Механизма» можно выделить следующие семы: функииональность, исправность, но бездушность, антигуманность. Отлаженная работа всех деталей Америки как «Механизма», по мнению Г. Д. Гребенщикова, не только обеспечивает экономическое процветание страны, но и влечет за собой потерю человеческой индивидуальности. Обладая чисто технической рациональностью, «Механизм» не принимает во внимание человеческий фактор, рассматривая человека лишь как деталь общего механизма. 


\section{Метафорическая модель «Америка-Организм» (биоморфный / антропоморфный)}

Метафорическая модель «Америка - Механизм» в тексте Г. Д. Гребенщикова пересекается с метафорической моделью «Америка - Организм». Иллюстрацией такого пересечения служит краткая авторская ремарка о Вашингтоне как о сложном техническом аппарате, «куда стекаются нервы и сосуды расстроенного организма мира» (ГРЕБЕНщиков-О: 4).

Первичное лингвокогнитивное исследование текста Г. Д. Гребенщикова репрезентирует перед нами метафору биоморфного «Организма». Америка предстает перед нами как организм, ограниченный примитивной физиологией живого существа и зависящий от окружающей среды: «Значение Америки настолько велико и для России и особенно для всего мира, что всякая ее болезнь была бы великим несчастьем для всего человечества» (ГРЕБЕНщиКов-Ч: 2). «...мы кружим все не по тем дорогам и как раз пересекаем центральные артерии города в тех местах, где нет движения» (ГРЕБЕНщиков-О: 2). «Вся Америка все еще питается ложью о прошлом России» (ГРЕБЕНщиков 2002: 250). Сферой-источником в данном случае служат представления о строении и функционировании живого организма, который существует за счет постоянных обменных процессов (питание, дыхание, реакции и т. д.). Выявление данной метафорической модели позволяет соотнести исследуемый концепт с физиологией организма, тем самым более наглядно представляя один из механизмов его экспликации.

Но дальнейшее исследование выявляет «Организм», который, кроме физиологии, характеризуется также человеческими когнитивными особенностями: силой воли, сочувствием, терпением. То есть в рамках рассматриваемого концепта происходит реализация антропоморфной метафорической модели «Америка - Человеческий организм»: «...перед страной во всем своем, американском, масштабе встали тяжкие проблемы, для разрешения которых нужна огромная сила воли и культурная вылержка» (ГРЕБЕНщиков-Ч: 5). «Америка в своем материальном благополучии совсем забыла о духовных радостях жизни» (ГРеБЕНщиков-Ч: 19). «Сколько Америка терпит паразитов, сколько она им благотворит» (ГРЕБЕНщиков-А: 4). Психологичность концеПта «Америка», его одушевление позволяют нам дополнительно расширить сферу-цель, наполняя ее новым содержанием.

Артефактная метафора «Механизма» репрезентирует концепт «Америка» как хорошо отлаженное устройство, где каждая деталь находится на своем месте и исправно выполняет возложенную на нее функцию. Суммарное действие всех деталей отточено, эффективно и рационально.

Биоморфная метафора «Организма» призвана помочь рассмотреть содержание концепта с точки зрения сущности природного происхождения. Сходство жизненных процессов, происходящих в организме, и его взаимодействие с внешней средой обеспечивает более понятный, а, следовательно, более точный перенос смыслов со сферы-источника на сферу-цель. 
Рассматриваемые метафорические модели объединяет и то, что и «Механизм», и «Организм» испытывают постоянную потребность в ресурсах. Несмотря на имплицитное предположение, что хорошо налаженный «Механизм» будет работать без сбоев, надежно и предсказуемо, он испытывает потребность в обслуживании (материалы, энергия, технологии), подобно тому, как невозможно существование «Организма» без воздуха, воды и еды. Кроме того, с точки зрения внутреннего устройства рассматриваемых образований все их части служат для общего целого. Но если «Америка - Механизм» эксплуатирует детали, не учитывая степень их изношенности и индивидуальные потребности, то «Америка - Организм» существует ради своих частей, для их блага: «Эта страна... человеческому горю широко сочувствует и дает все виды реальной, а не словесной только, помощиџ (ГРеБЕНщиков-А: 4).

\section{Концептуальный бленд «Американский Вавилон»}

Однако некоторые важные аспекты авторского понимания «Америки» не могут быть объяснены только теорией концептуальной метафоры. Смысл метафорического высказывания не всегда удается развернуть, пользуясь отображением сферы-источника на сферу-цель. Например, в 1950 г., вспоминая подробности основания иммигрантской деревни-колонии Чураевка в штате Коннектикут, Г. Д. Гребенщиков так объясняет свой отъезд из Нью-Йорка: «Потребовался только один год для того, чтобы убедиться в том, что великий современный Вавилон не для нас и мы не для Вавилона» (ГРеБенщиковК: 1). Понимание данного текста требует более детальной реконструкции. С этой точки зрения более адекватным инструментом для лингвокогнитивного анализа представляется механизм концептуальной интеграции, состоящий не из двух, а, как минимум, из четырех концептуальных структур, которые авторы теории называют ментальными пространствами (FAUCONNIERTURNER 2002). В результате «смешения» исходных ментальных пространств мы получаем бленд - качественно новый концептуальный конструкт, которым «удобно оперировать как единым целым» (СкРеБцовА 2011: 176).

Лингвокогнитивное проникновение в литературный контекст Г. Д. Гребенщикова позволяет нам выявить имплицитное содержание авторских суждений о формировании американской цивилизации: «Вся культура и цивилизация Америки созидалась коллективно, посланцами от всех народов мира» (ГРеБЕНщиков-В: 3). «И кто они эти фермеры? Либо сыны, либо внуки, либо правнуки пришельцев из далеких чуждых стран» (ГРеБенщиков-В: 4). «Пусть великая, многоплеменная Америка еще ближе и сердечнее приблизится к нашей душе» (ГРеБЕНщиков 5: 320). Неоднозначный процесс иммиграции, который на протяжении большей части истории Америки был основным источником роста населения и культурных изменений, создал в США уникальную мультиэтническую ситуацию полиязычия. Образ многоязычной, «многоплеменной» страны в когнитивном контексте Г. Гребенщикова прототипически 
наследуется от мифологических образов Вавилона и Вавилонской башни, возведение которой и привело к смешению языков, «так чтобы один не понимал речи другого» (Быт. 11:7).

Лингвокогнитивный анализ текста Г. Гребенщикова позволяет выявить индивидуально-авторский бленд «Американский Вавилон» (см. Рисунок 1).

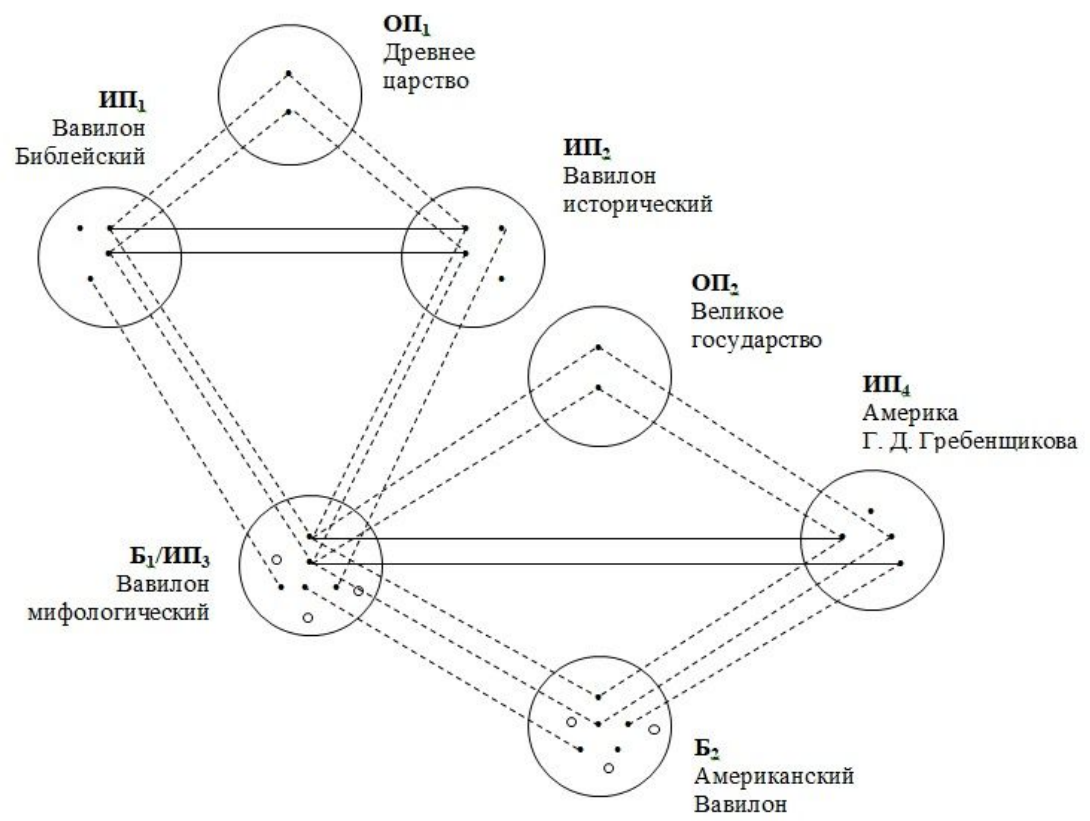

Рисунок 1. Концептуальная интеграция: АМЕРИКАНСКИЙ ВАВИЛОН

Рассматриваемый бленд «Американский Вавилон» $\left(5_{2}\right)$ является результатом смешения двух исходных ментальных пространств: Вавилон мифологический $\left(И_{3}\right)$ и Америка Г. Д. Гребенщикова $\left(И_{4}\right)$. Однако в картине мира Г. Д. Гребенщикова, как носителя христианской культуры, концептуальная структура Вавилон мифологический $\left(И_{3}\right)$ является результатом интеграции Вавилона Библейского $\left(И_{1}\right)$ и Вавилона исторического $\left({ }_{2}\right)$, как реально существовавшего государственного образования, то есть также представляет собой бленд $\left(5_{1}\right)$. При этом религиозный контекст образа Вавилона является первичным по отношению к историческому контексту, поскольку предпосылки научного поиска древнего Вавилона базировались на знании библейского текста (КЛЕНГЕЛЬ-БРАНДт 1991: 11).

Все эти взаимосвязи наглядно демонстрируют существенное свойство концептуальной интеграции: независимость бленда от исходных пространств и наличие у него собственных потенций к дальнейшему развитию. То есть оформившийся бленд «Вавилон мифологический» $\left(\mathrm{b}_{1}\right)$ может выступать исходным пространством для создания другого бленда. 
Это основание для метафоризации ментальных пространств содержится в общих пространствах $\left(\mathrm{O}_{1}, \mathrm{O}_{2}\right)$, отображающих наиболее абстрактные элементы, присущие исходным пространствам, участвующим в интеграции. Так, общее пространство Великое государство $\left(\mathrm{OП}_{2}\right)$ представлено номинациями, репрезентирующими родовое сходство Вавилона и индивидуальноавторского представления об Америке: полиязычие, или смешение языков, уже упоминаемое нами ранее, и великое государство.

Вавилон, великая держава древнего мира, центр науки, искусства, культуры, был одним из государств, сформировавших месопотамскую цивилизацию, которая оказала огромное влияние на общечеловеческую культуру. Известный востоковед-ассириолог В. А. Якобсон отмечает чрезвычайно высокий престиж Вавилонии, которая вплоть до новейшего времени «неизменно оставалась важной частью всех переднеазиатских империй...» (ЯкоБсон 2004: 56).

Величие Америки и ее значимость в мировом сообществе также является одним из основных признаков индивидуально-авторского концепта Г. Д. Гребенщикова: «Значение Америки настолько велико для всего мира, что всякая ее болезнь была бы великим несчастьем для всего человечества» (ГРеБЕнщиков-Ч: 2). Америка - «интернациональная страна, которая создала... величайшее из свободных государств на новом первобытном месте» (ГРеБЕНЩИКОВ 4: 406).

Кроме номинаций, представленных в ОП 2 , собранный материал позволяет также выделить общие элементы, «сплавляемые» в бленде «Американский Вавилон»: иентр науки и индустрии, богатство и грех. Однако при построении бленда не все элементы исходных пространств «сплавляются» в один. В качестве примера рассмотрим культуру как элемент, присутствующий в структурах исходных пространств ИП 3 и ИП 4 .

Древняя Вавилония известна своими достижениями в области математики, астрономии, медицины и других наук. Вместе с тем важнейшие культурные достижения человечества, которые переняла, развила и передала нам античная культура, также восходят к месопотамским прототипам (ЯкоБсон 2004: 42).

Однако культура Америки, согласно тексту Г. Д. Гребенщикова, не обладает тождественным набором характеристик. Бесспорно признавая достижения американской науки и техники, писатель отмечает недостаточную развитость сферы создания, распространения и сохранения духовных ценностей: «техника цивилизации в Америке великолепна, но культура здесь в зачатке» (ГРеБенщиков-Ч: 9). «Страна эта... в смысле оченки и продажи изящной литературы очень бедна...» (ГРеБенщиков 5: 382). «На каждом шагу вижу, как обесиенены настоящие дары культуры» (ГРеБЕнщиков-Ч: 8).

По этой причине мы не можем выделить в структуре ментального про-

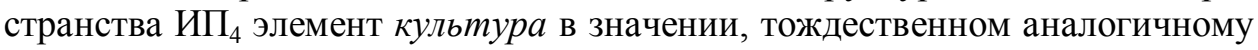
элементу в структуре ИП . То есть в данном случае «сплавления» не происходит. 
Таким образом, формирование бленда «Американский Вавилон» $\left(\mathrm{Б}_{2}\right)$ проходит в несколько этапов: 1) метафорическая проекция содержания исходных пространств ИП и ИП $_{4}$; ) отображение абстрактных элементов, присущих ИП и ИП $_{4}$, в общем пространстве $\mathrm{OП}_{2}$ : великое государство, полиязычие (смешение языков); 3 ) подключение к сформированной структуре $\mathrm{O}_{2}$ контекстуального содержания; 4) выделение в ИП и ИП $_{4}$ элементов, необходимых для построения бленда, и их последующее «сплавление»: иентр науки и индустрии, богатство и грех.

\section{Заключение}

Применение инструментов концептуальной метафоризации к когнитивному контексту Г. Д. Гребенщикова американского периода позволило выявить и сопоставить концептуальные метафоры: «Америка - Механизм» и «Америка - Организм». Однако сложность авторского понимания Америки потребовала привлечения разработок теории концептуальной интеграции. Результатом стала реконструкция авторского концептуального бленда «Американский Вавилон».

И в целом, метафорическая концептуализация, на наш взгляд, процесс двусторонний. С одной стороны, «расшифровывая» метафорические модели, заложенные в тексте, мы имеем возможность лучше понять авторский замысел. С другой, автор, используя метафорические аналогии, может вложить концептуально новые идеи в языковые формы, понятные читателю. Поэтому использование механизмов концептуальной метафоризации является эффективным лингвистическим инструментом для выявления имплицитных смыслов авторского текста.

\section{Источники}

ГРЕБЕНщИКОВ $=$ ГРЕБЕНщИКОВ Г. Д. Собрание сочинений в 6 mомах. Т. 1-6. Барнаул, 2013.

ГРеБЕнщиков 2002 = И. А. Бунин и Г. Д. Гребенщиков. Переписка. В кн.: С двух берегов. Русская литература ХХ века в России и за рубежом. Москва, 2002. 220-276.

ГРЕБЕНЩИКОВ-А = ГРЕБЕНщИКОВ Г. Д. Америка-страна тяже Лого труда. ГМИЛИКА. НВФ 16801/7.

ГРЕБЕНщИКОВ-В = ГРЕБЕНщИКОВ Г. Д. В просторах Америки. O философии быта. ГМИЛИКА. ОФ 56739/284.

ГРЕБЕНщИКОВ-К = ГРЕБЕНщИКОВ Г. Д. Как это было $и$ что получилось. ГМИЛИКА. ОФ 16015/020.

ГРЕБЕНЩИКОВ-О = ГРЕБЕНщИКОВ Г. Д. Опять по Америке. В столище мира. ГМИЛИКА. ОФ 56739/309.

ГРЕБЕНЩИКОВ-Ч = ГРЕБЕНщИКОВ Г. Д. Что Ждет Америку? ГМИЛИКА. ОФ 56739/ 257.

КЛЕНГЕЛЬ-БРАНДТ 1991 = КЛЕНГЕЛЬ-БРАНДТ Э. ВавилонсКая баиня. МосКва, 1991. 


\section{Литература}

ГлеБкин 2012 = ГлеБкин В. В. Метафора механизма и теория концептуальной метафоры Лакоффа-Джонсона. Вопросы языкознания 2012/3: 51-68.

ПОПОВА-СТЕРНИН 2007 = ПоПОВА З. Д., СТЕРНИН И. А. Семантико-когнитивный анализ языка. Воронеж, 2007.

Росов $2004=$ Росов В. А. Бельий храм на высоких горах. Очерки о русской эмиграции и сибирском писателе Георгии Гребенщикове. Санкт-Петербург, 2004.

СиРОТА 2007 = СиРОТА О. С. Проблемы сохранения и развития русской культуры в условиях эмиграции первой волны. АКД. Москва, 2007.

СКРЕБЦОВА 2011 = СКРЕБЦОВА Т. Г. Когнитивная лингвистика. СанКт-Петербург, 2011.

ЧЕРняЕВА 2015 = ЧЕРняЕВА Т. Г. Забытый русский писатель. О собрании сочинений Георгия Гребенщикова. Сибирские огни 2015/1: 161-171.

Якоьсон 2004 = ЯкоБсон В. А. Предисловие. В кн.: История древнего Востока. От ранних государственных образований до древних империй. Москва, 2004. 34-56.

FAUCONNIER-Turner 2002 = FAuCONNIER Gilles, Turner Mark: The Way We Think. Conceptual Blending and the Mind's Hidden Complexities. New York, 2002.

GIBBS 1996 = GIBBS Raymond: Why many concepts are metaphorical. Cognition 61 (1996): 309-319.

KöveCSES 2005 = KöveCSES Zoltán: Metaphor in Culture. Universality and Variation. Cambridge, 2005.

LAKOFF-JOHNSON 2003 = LAKOFF George, JOHnSON Mark: Metaphors We Live By. London, 2003. 